\title{
CONTRIBUIÇÕES DO ESTÁGIO SUPERVISIONADO E DO PIBID NA FORMAÇÃO DE PROFESSORES DE MATEMÁTICA
}

\section{CONTRIBUTIONS OF SUPERVISED PRACTICE AND PIBID IN MATH TEACHERS EDUCATION}

Danielly Fraga Santana, Rosana Martins Matiuzzi, Dilza Côco

Instituto Federal do Espírito Santo - câmpus Vitória

E-mail: danielly.fraga@live.com, rosanamattiuzzi@gmail.com, dilzacoco@gmail.com

\section{Resumo}

O artigo apresenta dados de uma pesquisa maior sobre formação docente, desenvolvida no Instituto Federal do Espírito Santo, campus Vitória. O texto tem por objetivo discutir aprendizagens docentes de licenciandos em Matemática construídas em atividades do Estágio Supervisionado e de ações do Programa Institucional de Bolsa de Iniciação à Docência. Trata-se de pesquisa qualitativa, cujo corpus é composto por relatórios escritos e outros textos elaborados por licenciandos desde o ano de 2011. Enunciados que se integram nesses relatórios são analisados a partir de pressupostos teóricos de Bakhtin e Shulman. Os dados apontam que oportunizar diferentes experiências na escola e privilegiar diálogo e reflexões sobre elas favorecem a construção de conhecimentos da docência.

Palavras-chave: Matemática. aprendizagem docente. enunciados.

\section{Abstract}

The paper presents data from a larger research about teacher training, developed at Federal Institute of Espírito Santo, Vitória campus. The paper aims at discussing teachers learning of Math undergraduates built in supervised practice activities and actions of the Institutional Scholarship Program for Beginner Teachers, in Brazil. It is a qualitative research, consisting of written reports and other texts prepared by students since 2011. Enunciations that are part of these reports are analyzed from theoretical assumptions of Bakhtin and Shulman. The data show that provide different experiences in the school context and give priority to dialogue and reflection on these experiences favors the building of teaching knowledge.

Palavras-chave: Mathematics. teacher learning. enunciations. 


\section{INTRODUÇÃO}

A inserção de licenciandos em Matemática do Instituto Federal de Educação do Espírito Santo (IFES), câmpus Vitória, em escolas da Educação Básica (Ensino Fundamental), seja por meio de atividades do Estágio Supervisionado ou por ações vinculadas ao Programa Institucional de Bolsa de Iniciação à Docência (Pibid), tem possibilitado a construção de narrativas repletas de experiências de professores e/ou futuros professores. Acreditamos que essas narrativas explicitam aprendizagens coletivas, ou seja, mostram percursos de professores regentes e de licenciandos. Nesse último caso, é importante reconhecer que os sujeitos muitas vezes ocupam posições transitórias, pois ora assumem a condição de alunos, em outros momentos são percebidos como professores e muitas vezes assumem essas posições simultâneas.

Considerando ideias de Bakhtin (2003) a respeito de conceitos como enunciado, vozes, diálogo, dentre outros que segundo o autor integram o processo formativo dos sujeitos, pudemos entrever no conteúdo discursivo dos enunciados apresentados nesse estudo as vivências sociais e as aprendizagens da docência por meio do uso da palavra. Desse modo, consideramos que a palavra assume lugar privilegiado nos processos de formação, pois possibilita aos sujeitos narrar experiências, recuperar e atualizar memórias, evidenciar percursos e ações, explicitar crenças e outros elementos que integram o processo reflexivo e constitutivo da identidade docente.

Considerando a potência da palavra, este texto tem por objetivo analisar enunciados produzidos por licenciandos em Matemática sobre experiências vivenciadas em salas de aula da Educação Básica, na etapa do Ensino Fundamental. O registro e a reflexão sobre tais experiências tornam-se importantes no mapeamento de desafios e possibilidades enfrentados por licenciandos na formação inicial, quando entram em contato com o contexto escolar. Além disso, essas experiências sinalizam elementos que integram o processo de construção de conhecimentos da docência, que tem repercussões na constituição da identidade profissional dos licenciandos. 


\section{O CAMINHO DA PESQUISA: APONTAMENTOS TEÓRICO-METODOLÓGICOS}

Nesse artigo nos propusemos a compreender, por meio de um estudo comparativo, as contribuições das atividades do Estágio Supervisionado e do Pibid para aprendizagens docentes e repercussões na constituição da identidade profissional de licenciandos em Matemática do Instituto Federal de Educação, Ciência e Tecnologia do Espírito Santo câmpus Vitória. $\mathrm{O}$ artigo tomou para análise enunciados produzidos pelos licenciandos no contexto de ações das disciplinas de Estágio Supervisionado I e II, ofertadas aos estudantes nos 5 e 60 períodos do curso de licenciatura em Matemática, com foco nos anos finais do Ensino Fundamental. Tal escolha justifica-se com a metodologia utilizada pelas professoras destas disciplinas, que propunham aos licenciandos a constante produção de textos (orais e escritos) sobre as experiências de estágio vivenciadas. Essa prática se baseava em pressupostos de Bakhtin (2003, p. 307), que defendia que "o texto é a realidade imediata (realidade do pensamento e das vivências)". Desse modo, os sujeitos (licenciandos), por meio de textos refletiam sobre ações observadas e experienciadas nas escolas durante o Estágio Supervisionado e explicitavam por meio dos textos suas reflexões em torno dos desafios enfrentados e também das aprendizagens da docência.

Consideramos ainda o fato de a turma ser composta por, além dos bolsistas do Pibid, alunos que não possuíam experiência em sala de aula e que tiveram pela via do Estágio Supervisionado seus primeiros contatos com o cotidiano escolar enquanto futuros docentes. Dessa forma, o objetivo foi delinear contribuições que as atividades de estágio supervisionado e do Pibid proporcionam à formação dos licenciandos e a suas respectivas percepções sobre a profissão docente. As análises foram construídas a partir da perspectiva discursiva de linguagem postulada pelo teórico russo Mikhail Bakhtin, que apostava na potencialidade do diálogo no processo de formação humana. Corroboramos com a teoria deste autor, pois defendemos que por meio da linguagem o sujeito tem a possibilidade de se expressar e se posicionar frente às situações vividas e colocar à vista suas compreensões. 
Para além dos fundamentos da linguagem, buscamos olhar esses enunciados a partir de indicações de Shulman (2005) que realçam que a formação docente integra diferentes conhecimentos, em especial, aqueles do conteúdo, pedagógicos e pedagógicos do conteúdo.

A partir dessa base teórica tomamos dois conjuntos de relatórios, o primeiro produzido por licenciandos que participavam apenas de atividades de estágio supervisionado e o segundo escrito por licenciandos que tinham realizado atividades de estágio supervisionado e também do Pibid. Após a leitura na íntegra dos textos, privilegiamos em nossa análise quatro relatórios, considerando os limites de exposição desse artigo. Esses textos apresentavam a ocorrência de enunciados reflexivos e indicavam aspectos de aprendizagem docente. Os autores foram identificados com nomes fictícios em conformidade com o previsto no protocolo ético de pesquisa com seres humanos.

\section{FORMAÇÃO DE PROFESSORES DE MATEMÁTICA NO IFES/VITÓRIA}

O Ifes construiu uma sólida e centenária trajetória no campo da educação técnica e tecnológica no Espírito Santo, mas na área das licenciaturas essa trajetória pode ser considerada recente. Focalizando a atuação contemporânea do câmpus Vitória, são ofertadas vagas para os cursos de licenciatura em Matemática, desde o ano de 2008, e licenciatura em Letras - Português, a partir de 2011.

Em relação ao curso de licenciatura em Matemática, este foi pensado a partir da perspectiva humanística, onde a formação dos sujeitos necessita contemplar a articulação das várias dimensões do conhecimento. Desse modo, a proposta do curso parte da premissa de que

[...] um determinado saber a respeito de um determinado objeto ou situação não resulta da soma de elementos fornecidos pelas várias disciplinas, ao contrário, se estabelece na/pela articulação entre os elementos que concorrem solidariamente e que transcendem cada uma das 
disciplinas (PROJETO POLÍTICO PEDAGÓGICO, 2008, p. 9).

Essa forma de compreender a construção do conhecimento, em especial os conhecimentos da docência, possibilita dialogar com proposições de autores como Severino (2001) que defende que

os ambientes de formação dos professores devem propiciar, ao mesmo tempo, vivências reais da prática educativa, assim como garantir familiaridade com as práticas tecnológicas e científicas direta ou indiretamente envolvidas. Também o exercício crítico, o desenvolvimento de atitudes e valores, a promoção do sentido maior de cidadania, são mais amplos e efetivamente realizados diante de situações reais, que podem igualmente ser encontradas ou suscitadas nas condições de formação (SEVERINO, 2001, p. 20).

Nesse contexto de premissas e demandas que envolvem a complexidade da formação docente, o Ifes estruturou a proposta do curso de licenciatura em Matemática a partir de quatro eixos, a saber: eixo 1 - conhecimentos científicos específicos da Matemática e dos fundamentos da Educação; eixo 2 - prática como componente curricular; eixo 3 - estágio supervisionado e eixo 4 - atividades complementares. Essa organização destaca a importância e a necessidade de vivências, ao longo do processo formativo dos licenciandos, dentro do ambiente escolar da educação básica, como as que iremos relatar nos próximos tópicos.

\section{ESTÁGIO SUPERVISIONADO: PERCURSOS E AÇÕES DE INSERÇÃO DE LICENCIANDOS NO ESPAÇO ESCOLAR}

O curso de licenciatura em Matemática do Ifes Vitória tem, desde a sua criação, firmado parcerias com escolas da rede pública da Grande Vitória, com o objetivo de desenvolver diferentes atividades, dentre elas, as de estágio supervisionado. Destacamos que esses 
dados (Tabela 1) relacionam informações até o ano de 2014, por termos realizado consulta ao acervo de documentos até esse referido ano; porém lembramos que as fontes da pesquisa apresentam documentos de outros anos.

Tabela 1. Número de escolas envolvidas em atividades de estágio supervisionado.

\begin{tabular}{|c|c|c|}
\hline Ano & Escolas estaduais & Escolas municipais \\
\hline $2012 / 1$ & 03 & 02 \\
\hline $2012 / 2$ & 03 & 01 \\
\hline $2013 / 1$ & 03 & 04 \\
\hline $2013 / 2$ & 03 & 03 \\
\hline $2014 / 1$ & 01 & 02 \\
\hline $2014 / 2$ & 01 & 01 \\
\hline
\end{tabular}

Fonte da tabela: Dados da pesquisa.

As atividades de estágio supervisionado são organizadas em quatro momentos, e embora cada momento possua um objetivo específico e distinto, eles mantêm estreita articulação. 0 primeiro consiste em estudos teóricos e reflexões com os licenciandos sobre aspectos da cultura escolar. A partir dessa fase os licenciandos se inserem no contexto das escolas de Ensino Fundamental para desenvolverem atividades de observação e coparticipação em aulas de Matemática. Após a realização dos trabalhos nas unidades de ensino, os licenciandos retornam à instituição formadora para encontros coletivos de socialização e reflexão das experiências vividas e, por fim, elaboram relatos escritos das experiências, expondo suas aprendizagens, desafios e reflexões. Essa forma de organização exige dos sujeitos constante produção de textos orais e escritos. Reafirmamos que somente por meio de textos é possível compreender o processo de aprendizagem da docência. Desse modo, é por meio de textos que os sujeitos se exprimem, ou seja, cria textos. 


\section{O PIBID DE MATEMÁtICA NO IFES/VITÓRIA: PERCURSOS PARA A APRENDIZAGEM DA DOCÊNCIA}

O Pibid consiste em uma das ações do Governo Federal para incentivar a adesão de estudantes ao campo das licenciaturas. Em termos específicos constitui-se num "programa de incentivo e valorização do magistério e de aprimoramento do processo de formação de docentes para a educação básica" (CAPES, 2012, p. 04) que articula as vertentes: formação de qualidade; integração entre pós-graduação, formação de professores e escola básica; e produção de conhecimento.

O curso de licenciatura em Matemática do Ifes, câmpus Vitória, aderiu ao programa no ano de 2009. O início das atividades focalizou ações no ensino fundamental e se desenvolveu em três escolas municipais de Vitória. Nesta ocasião foram ofertadas 15 vagas, implementadas em 2010. Em 2011 a ampliação do programa permitiu a aprovação de um subprojeto disponibilizando mais 15 vagas para atividades no Ensino Médio em três escolas estaduais. Em 2012, foi renovado o projeto do Ensino Fundamental com ampliação das vagas para 18 bolsistas. A partir dessa renovação, a totalidade dos 33 bolsistas do programa, vinculados aos Ensinos Fundamental e Médio, passaram a desenvolver atividades em várias unidades da rede pública parceiras do programa.

As atividades do Pibid Matemática são coordenadas de forma semelhante e articuladas por dois professores do curso. Os bolsistas possuem uma carga horária de 10 horas semanais, subdivididas em 6 horas de atividades em sala de aula, 2 horas de planejamento com o professor regente e 2 horas de planejamento com o coordenador do programa, ou para a produção de artigos, relatórios e planejamento de atividades de coparticipação.

A inserção dos bolsistas ao programa segue uma sequência de ações, como a definição da escola de atuação do bolsista pelo coordenador, ou a definição de turmas a serem acompanhadas na unidade de ensino, realizada junto com o professor supervisor de cada escola. A partir dessa fase, por orientação dos coordenadores do Pibid, o trabalho em sala de 
aula é realizado com os bolsistas em duplas. Inicialmente é sugerido um período de observação com o intuito de estabelecer aproximações com os alunos e também para a compreensão da dinâmica de funcionamento escolar. A partir dessas observações, são pensadas sugestões de ações que possam favorecer o processo de ensino-aprendizagem em Matemática. Essas sugestões podem ser propostas tanto por parte dos bolsistas quanto pelo professor regente.

Como forma de documentação, são produzidos relatórios trimestrais, semestrais e anuais das experiências. Estes relatórios devem conter informações e reflexões que o bolsista considere pertinentes a sua vivência no espaço escolar. Nessa dinâmica, o projeto Pibid/Ifes promove, com as escolas participantes, a inserção dos licenciandos em Matemática no cotidiano escolar, privilegia o ensino e a aprendizagem dos envolvidos no programa e permite a construção de ambientes favoráveis à troca de experiências.

\section{NARRATIVAS DE APRENDIZAGENS DOCENTES DE MATEMÁTICA: O ESTÁGIO SUPERVISIONADO E O PIBID EM FOCO}

Considerando a trajetória e organização das atividades de estágio supervisionado e do Pibid, do curso de licenciatura em Matemática do IFES, iremos neste tópico apresentar narrativas que sinalizam aprendizagens docentes. Para a análise, selecionamos quatro relatórios, cujos autores possuíam distintas trajetórias de aproximação com o contexto escolar, na condição de futuros professores.

Um dos relatórios foi produzido por um licenciando que teve oportunidade de desenvolver atividades na escola, apenas pela via do Estágio Supervisionado, denominado por nós ${ }^{1}$ de Alberto. As narrativas de Alberto foram produzidas a partir de atividades de estágio supervisionado desenvolvidas em turmas da modalidade de Educação de Jovens e Adultos

1 É importante lembrar que a adoção de nomes fictícios para identificar os sujeitos do estudo, está prevista no protocolo ético da pesquisa, e tem como propósito preservar a identidade dos participantes, conforme já indicamos. 
(EJA), no turno noturno, durante seis semanas consecutivas, em uma escola da rede municipal de Vitória. Em seu relatório, ele descreve com detalhes as condições da escola em que atuou e suas percepções sobre interações aluno/professor que observou nas aulas de Matemática. Além das descrições da escola em que estagiou, Alberto manifestou sua indignação com o movimento de greve dos servidores da educação federal, que ocorreu no ano de 2012. Para ele (p. 6-7),

fazer greve é direito, desde quando não fere a ética da educação. Desde quando os professores sonham com um país melhor se os mesmos se negam a dar a educação que eles tanto dizem que é fundamental para a mudança? Como uma educação dita fajuta piorando ainda mais ela? Não aceito e nunca aceitarei greve!

As professoras coordenadoras das atividades de estágio, ao realizarem a leitura dos relatórios, registravam observações e comentários sobre diferentes aspectos explicitados nesses textos, como questões de forma e também de conteúdo. E diante da afirmação do licenciando não poderiam ficar indiferentes e registraram a seguinte observação: "Como assim?". Uma das atividades de encerramento da disciplina consistia no retorno dos relatórios aos seus respectivos autores para que pudessem conhecer as observações das professoras coordenadoras, e se desejassem, poderiam retomar o diálogo sobre os elogios, questionamentos e indicações apresentadas. Essa estratégia tinha por objetivo que os sujeitos pudessem perceber seus limites e potencialidades e nessa proposta de continuidade do diálogo, avançar em seus conhecimentos. Ao se deparar com o questionamento da professora, Alberto sente necessidade de apresentar contrapalavras e redige uma resposta manuscrita, dizendo:

Quando relatei meu pensamento sobre a greve, me coloquei somente na posição de aluno prejudicado, esquecendo de se colocar na posição de professor precarizado. Ao conversar com a professora [...] ela me fez repensar sobre o tema, algo que sempre relutei em aceitar. Percebi que a 
greve é prejuízo em ambas as partes, apesar de recair mais para o lado do aluno. Certamente, a pequena conversa com a professora pesou bastante no modo de como visualizarei a greve a partir de agora (ALBERTO, 2012).

Desse modo, podemos entrever o que Bakhtin (2003, p. 334) nos aponta sobre o processo de compreensão responsiva inerente a constituição de enunciados plenos. Toda palavra pressupõe "ser ouvida, entendida, respondida e mais uma vez responder à resposta". Nesse processo de uso e interação com a palavra alheia temos a oportunidade de ampliar nosso universo de compreensões e percepções sobre o mundo e a vida. O diálogo com a professora possibilitou a Alberto partilhar de um excedente de visão que só o outro pode nos oferecer. Assim, o texto do licenciando evidencia a importância permanente do diálogo nos processos de formação, em especial, nos processos de formação de professores que envolvem conhecimentos de várias dimensões.

O segundo relatório que tomamos para análise foi produzido por Bruno. Esse licenciando participou de várias atividades do curso desenvolvidas em escolas da Educação Básica, como as de estágio supervisionado e também do Pibid (Ensino Fundamental e Médio). Em suas narrativas, Bruno mostra reflexões que evidenciam aprendizagens docentes importantes, pois são conhecimentos que perpassam o processo de ensino e de aprendizagem em Matemática.

Quando entrei no curso achava que a matemática tradicional era a melhor de todas, mesmo que eu não aprendesse nada. No início do curso tomei um choque quando vi que alguns professores pediam para fazermos exercícios no quadro. Ficava todo envergonhado e pressionado a resolver o exercício de forma correta. Mas aos poucos fui percebendo que essa atitude do professor era para que eu perdesse o medo de falar em público (BRUNO, 2012, p. 3).

Assim, Bruno explicita em suas narrativas que as ações docentes dos professores do curso de 
licenciatura o levaram a reformular seus conceitos, pois inicialmente acreditava que o conhecimento do conteúdo matemático era o principal elemento na formação docente. Aos poucos, com as atividades do curso, foi possível reconhecer aprendizagens sobre o fazer pedagógico. Em outros trechos do seu relatório, podemos perceber que as várias experiências vivenciadas na condição de futuro docente dentro das escolas onde realizou atividades do Pibid e de estágio supervisionado, também colaboram para a construção de conhecimentos da docência.

Para mim voltar a Escola de Ensino Fundamental foi um choque de realidade, pois já conhecia turmas de Ensino Médio, por atuação do Pibid, em 2011, e esperava que os alunos desse nível de ensino fossem muito parecidos com os do Ensino Médio. Afinal, pertencia a mesma escola [...] Senti uma mudança forte porque não estou acostumado a ser chamado de professor e eles olham para mim como se eu fosse uma referência para a turma. [...] [Os alunos] são muito indisciplinados e carentes. [...] Para superar essas barreiras, percebi que preciso: ganhar o coração deles, de certo modo se importar com o que acontece fora da escola e evitar gritar na sala, pois eles copiam o comportamento do professor (BRUNO, 2012, p.4).

Esses enunciados expressam preocupações do licenciando com o processo de ensino aprendizagem. As diferentes experiências educacionais de Bruno, vivenciadas na condição de futuro docente, parecem ter-lhe provido condições de reflexão sobre suas atitudes/ações docentes. Esse modo de compreender relações professor-aluno se apresenta de forma madura e mobiliza o licenciando na busca de estratégias didáticas que ofereçam melhores condições de interação, o que remete à ideia sobre a necessidade de considerar conhecimentos sobre os alunos, como nos indica Shulman (2005).

Esses enunciados de Alberto e de Bruno nos mostram a potencialidade da escrita, numa perspectiva discursiva de linguagem, para investigar o processo de aprendizagens da docência. Por meio da produção dos relatórios podemos conhecer seus percursos, desafios, 
experiências, dúvidas e ainda provocar reflexões que levam ao desenvolvimento profissional dos licenciandos. Esse modo de investigar as aprendizagens docentes dialoga com proposições como de Ponte (1998, p. 5), quando afirma que

O conhecimento profissional do professor [pode ser] estudado de diversas maneiras. Uma, que considero bastante interessante, é o uso de narrativas sobre situações de ensino-aprendizagem. Narrativas são relatos de experiências vividas, onde se evidencia as dificuldades vividas pelos actores, bem como a forma como resolveram as situações em que estiveram envolvidos. As narrativas são uma forma natural de organizar o nosso conhecimento experiencial e, por isso, são de grande interesse no estudo do conhecimento do professor.

Considerando essa relevância e potencialidade das narrativas para o processo de compreensão das aprendizagens da docência, apresentamos outros extratos de textos que confirmam contribuições dessa metodologia de investigação. Nesse sentido, apresentamos trechos do relatório de estágio supervisionado produzido pelo licenciando Laerte. É importante dizer que esse licenciando atuava em várias atividades extras do curso, como oficineiro do Programa Mais Educação em escolas municipais, bolsista do Pibid e também bolsista do Programa de Iniciação Científica. Considerando essas várias experiências, suas narrativas são significativas para compreendermos como aprendizagens da docência são formuladas e sistematizadas durante a formação inicial, com especial atenção para atividades de estágio supervisionado, pois estas são garantidas a todos os licenciandos. Em um dos trechos do relatório de Laerte encontramos enunciados importantes como:

Nesta aula [correção de exercícios no dia 14-03-2013 em uma turma de 8a série], me chamou atenção a forma com que a professora trata os alunos, os termos que ela usa e a desenvoltura deles perante a matemática. Como a atividade foi realizada em dupla, os alunos também são dispostos dessa forma para correção. Os alunos recebem a atividade escrita de volta, para que acompanhem as perguntas e que eles mesmos corrijam suas 
atividades. Essa proposta me causou espanto, mas os alunos encararam naturalmente, o que aponta que esta metodologia é um hábito durante as correções. Além disso, os alunos são rigorosos e coerentes com suas correções, o que me deixou bastante surpreso (LAERTE, 2013, p. 11-12).

Esse relato demonstra aprendizagem sobre a relação professor-aluno nas práticas educativas e elementos metodológicos de organização da aula. Mesmo que a ação da professora regente tenha inicialmente provocado surpresa ao licenciando, em relação à atuação dos alunos na correção dos exercícios, o mesmo percebeu possibilidades interessantes quando nota a responsabilidade dos discentes nessa dinâmica. Na sequência de seu relatório podemos identificar outros enunciados que sinalizam que as atividades de estágio supervisionado foram ricas de aprendizagens de diversas naturezas.

A primeira questão a ser corrigida apresentava uma empresa que produzia sempre $20 \%$ a mais que o mês anterior. A pergunta apresentava que a produção em 1999 foi de 100.000 e solicitava que o aluno fizesse a produção anual até o ano de 2004.

O primeiro passo [apresentado pela professora] foi calcular o acréscimo de 1999 para 2000, que pode ser determinado por $20 \%$ de $100.000=$ $20 / 100.100 .000=20.000$. Assim, a produção de 20.000 é dada por 100.000 $+20.000=120.000$. Nesse momento, sugeri propositalmente, que a produção de 2001 também fosse dada por $120.000+20.000$, pois havia observado que alguns alunos tinham feito dessa forma. A professora rapidamente entendeu o objetivo da minha pergunta e perguntou a turma se estava certo. Os alunos corrigiram-me dizendo que os $20 \%$ são referentes ao ano anterior, e por isso não podem ser constantes.

Dessa forma, a professora montou uma tabela, na qual o aluno somava a produção do ano anterior com o acréscimo referente aos $20 \%$ de crescimento. Durante o preenchimento dessa tabela, a professora chama os alunos pelos nomes e incentiva a continuar a correção oralmente. Essa estratégia incentiva os alunos a prestar atenção na correção e não 
dispersarem da dinâmica, uma vez que estão em duplas. Quando solicitados, os alunos que corrigem não tem medo de errar as respostas, o que indica que há um hábito nessa dinâmica. Ao fim do preenchimento a professora comentou que esse conteúdo estudado introduz a ideia de função exponencial e progressão geométrica. Achei esse comentário pertinente, pois mostra para os alunos que os conteúdos matemáticos não estão isolados, embora sejam ensinados de forma fragmentada na educação básica (LAERTE, 2013, p. 12-13).

Esses enunciados mostram que Laerte assume uma posição ativa na sala de aula onde realizou o estágio, pois observa as respostas registradas pelos alunos, apresenta proposição que mobiliza respostas dos alunos e da professora regente, fica atento a ações, vocabulário e formas de interação da professora com a turma, bem como percebe o tratamento do erro no desenvolvimento das aulas. Desse modo, indica que a aprendizagem da docência não se limita ao conhecimento do conteúdo matemático, mas de vários outros aspectos da dimensão pedagógica que integram o fazer docente. Outro dado importante pontuado por Laerte refere-se ao domínio de conhecimentos do currículo manifestado pela regente. Esse tipo de conhecimento pode ser identificado nas relações estabelecidas entre o conteúdo da aula e conteúdos sobre função exponencial e progressão geométrica. Desse modo, a professora demonstra conhecer o currículo, pois faz relações com assuntos anteriores e posteriores ao que estava sendo explorado na aula.

Em outro relatório selecionado para nossas análises encontramos narrativas ricas de detalhes que indicam aprendizagens docentes da licencianda Ravena. Esta realizou estágio com a mesma regente que Laerte, porém no ano de 2014. Outro dado interessante é que Ravena não acumulava experiência em atividades extras ao curso, como as apresentadas por Laerte, pois trabalhava como técnica industrial em uma empresa privada. Desse modo, sua disponibilidade ficava restrita as atividades regulares do curso. Vale destacar que essa escola recebia alunos para atividades de estágio supervisionado e Pibid desde o ano de 2011, portanto a unidade de ensino tinha experiência no acolhimento de licenciandos no contexto 
da dinâmica escolar.

No relatório de Ravena encontramos narrativas que indicam a importância dos licenciandos participarem de diferentes momentos da rotina escolar, desde os momentos de planejamento das aulas até o respectivo desenvolvimento e avaliação das atividades educativas.

Acompanhei os momentos que a professora planejava as aulas, mas não quis me intrometer muito. Preferi observar. Em alguns momentos me atrevi a dar palpites, mas para dizer a verdade não me sentia a vontade para palpitar, acho que ela é uma excelente profissional e não queria interferir no trabalho dela. O planejamento que mais opinei foi a aula de números decimais. Ela estava pensando em como explicar para os alunos que 0,2 é maior que 0,125 , por exemplo. Ela estava temendo que eles considerassem apenas o 2 e o 125 na comparação. Então sugeri que ela poderia orientar os alunos a completarem as casas decimais com zeros e fazer a comparação. Assim, a comparação ficaria entre 0,200 e 0,125, então ficaria mais nítido quem é o maior. Ela adorou a ideia e eu fiquei vaidosa com a contribuição (RAVENA, 2014, p. 14).

O relato de Ravena nos indica que licenciandos têm oportunidade de aprendizagens em diferentes situações do cotidiano escolar, como os momentos de planejamento das aulas. Nesse extrato podemos notar que Ravena constrói percepção positiva do trabalho docente a partir da observação da atuação da regente. Além desse aspecto, os enunciados também indicam que a dúvida explicitada pela professora sobre estratégias de ensino para abordar números decimais demandou uma resposta da licencianda. Nesse processo de interação se aventura em fazer indicações metodológicas para explorar o assunto. Assim, notamos que a interação e o diálogo com a professora regente, no momento do planejamento, constituíram boa oportunidade de aprendizagem para Ravena, bem como autorreconhecimento, pois ficou envaidecida com a aprovação de sua proposta pela professora que considerava 
excelente.

Em outro excerto do relatório, a licencianda continua explicitando suas aprendizagens sobre o fazer docente e também suas percepções sobre os alunos.

Não posso deixar de falar de outra aula que para mim foi uma lição. A aula era de números decimais e depois de planejar a aula junto com a professora decidimos como ministrar. Pedimos que os alunos trouxessem um pedaço de barbante ou fita para a escola. Antes de começar a falar dos números decimais (eles já tinham uma noção de números decimais, nas aulas de proporção de fração apareceram divisões com números decimais e a professora sempre frisava o nome das casas decimais também) cortamos o barbante em tamanhos diferentes de $1 \mathrm{~m}, 0,5 \mathrm{~m}, 0,1 \mathrm{~m}$ e 0,01 m. A partir dos diferentes tamanhos e quantos menores cabiam dentro dos maiores a ideia foi se fixando e eles foram entendendo. E no final de tudo eles conseguiram perceber que milésimos é menor que centésimo. Muitos tiveram dificuldade com as contas, mas entenderam o conceito. A lição para mim foi que eu duvidei que eles compreendessem o conceito. Eu fui categórica em dizer que iriam falar que milésimos é maior que centésimos. Eu subestimei os meninos. Durante muitas aulas eu vi as dificuldades dos alunos que para mim pareciam muito simples e julguei que teriam dificuldade, mas me enganei. Ainda bem que eu estava errada (RAVENA, 2014, p. 11).

Esses enunciados apontam que no Estágio Supervisionado Ravena teve oportunidade de observar ações didáticas que demonstram a importância do professor dominar conhecimentos didáticos do conteúdo. Segundo Shulman (2005) esse tipo de conhecimento articula elementos do conteúdo e da didática, com o objetivo de propiciar uma melhor compreensão de determinados assuntos, em termos de organização, de representação, levando em consideração características dos alunos, como condições de interesse e capacidade. A licencianda ainda pode reformular seus pressupostos em relação ao potencial 
dos alunos em compreender o conceito de números decimais, pois percebeu que as estratégias de ensino utilizadas pela professora favoreceram a aprendizagem do assunto. Desse modo, pensar em boas condições de ensino acreditando na capacidade de aprendizagem dos alunos é fundamental para todo o processo de trabalho educativo.

\section{CONCLUSÃO}

Durante a realização da pesquisa encontramos diferentes percursos do processo de aprendizagens profissionais e de constituição da identidade docente dos sujeitos do estudo. Essas diferenças se iniciaram no próprio processo de inserção nas escolas de Ensino Fundamental, pois alguns realizaram o estágio em unidades da modalidade EJA, outros em escolas de ensino regular, e outros já se ambientavam a mais tempo com o ambiente escolar, devido a inserção pela via do Pibid ou de outras atividades.

O Estágio Supervisionado se apresenta como um importante caminho na inserção do licenciando no espaço escolar e consequentemente na formação docente. A estruturação da disciplina possibilita vivências de situações didáticas numa sala de aula de Matemática, produção de textos orais e escritos, e a socialização das experiências no retorno à instituição formadora com o objetivo de promover reflexão sobre os aspectos que compõem a constituição da identidade docente. No caso de Alberto, essa dinâmica permitiu que as professoras de estágio fizessem indagações que o levaram a refletir sobre sua visão, ainda de aluno, a respeito da greve. Ao contrário de Alberto, os enunciados de Ravena revelam uma postura de professor em formação, quando apresenta alternativas de explicação de um conteúdo e quando valoriza o aprendizado dos alunos.

Em relação ao Pibid, podemos entendê-lo como uma via de acesso ao ambiente escolar que oportuniza aos licenciandos momentos de observação, planejamento, ensino e aprendizagem numa dinâmica de reflexão crítica. Bruno traz em seus relatos indícios dessa reflexão quando fala de se reconhecer professor, de ser referência e da preocupação com o 
aluno. Laerte, por sua vez, evidencia aspectos de ensino e aprendizagem quando contribui com questionamentos durante a aula incentivando os alunos ao desenvolvimento da argumentação.

As narrativas apresentadas e analisadas neste texto revelam experiências de licenciandos vividas, experimentadas, dialogadas com sujeitos da escola básica. Explicitam aprendizagens e compreensões das práticas educativas de ensino de Matemática a partir de um conjunto de vozes dos alunos e dos professores que habitam o espaço-tempo da sala de aula. Desse modo, o excedente de visão construído a partir do lugar que ocupa nesse contexto, ou seja, a posição de licenciando, de estagiário, de futuro docente, tem condições de elaborar e reconstruir percepções e conhecimentos necessários ao fazer profissional do professor.

Por fim os licenciandos avaliaram a inserção no ambiente escolar como uma experiência positiva. Aqueles que tiveram o primeiro contato com a escola pela via do estágio relataram a novidade e em alguns momentos a estranheza que o novo ambiente thes proporcionou na condição de futuros docentes. Cabe registrar que os dados e análises apresentados neste texto referem-se a um período específico da pesquisa, contudo, como se trata de pesquisa contínua, ainda em desenvolvimento, nossas conclusões são parciais. Outras reflexões podem ser encontradas em produções como de Côco e Silva (2015).

\section{AGRADECIMENTOS}

Este texto integra a produção de trabalhos de pesquisa vinculados ao Grupo de Estudos em Práticas Pedagógicas de Matemática (GRUPEM) do Ifes, câmpus Vitória. Neste contexto de produção de conhecimento, agradecemos o apoio financeiro do Fundo de Apoio a Ciência e Tecnologia de Vitória (FACITEC) às produções oriundas de iniciação científica de MATIUZZI; CÔCO (2013) e SANTANA; CÔCO (2013). 


\section{REFERÊNCIAS}

BAKHTIN, M. Estética da criação verbal. São Paulo: Martins Fontes, 2003.

CÔCO, Dilza; SILVA, Sandra Aparecida Fraga da. Estágio supervisionado e aprendizagem da docência: vivências e reflexões de uma licencianda de matemática. XIV Congresso Interamericano de Educação Matemática. México, Chiappas, 2015. Anais. Disponível em: <http://xiv.ciaem-iacme.org/index.php/xiv_ciaem/xiv_ciaem/paper/viewFile/831/349>.

Acesso em: 15 maio de 2015.

INSTITUTO FEDERAL DE EDUCAÇÃO DO ESPÍRITO SANTO. Projeto Político-Pedagógico, Licenciatura em Matemática. Vitória, 2008.

PONTE, J. P. Da formação ao desenvolvimento profissional. Em: Actas do ProfMat 98. Lisboa: APM, 1998. Disponível em: <http://www.educ.fc.ul.pt/docentes/jponte/artigos-portemas.htm>. Acesso em: 25 mar. 2013.

MATTIUZZI, R. M.; CÔCO, D. Estágio Supervisionado e Pibid no contexto da licenciatura em matemática: ações e reflexões. Em: Jornada de Iniciação Científica, Desenvolvimento Tecnológico e Inovação do Ifes, VIII, 2013, Ifes Campus Serra. Anais. Serra - ES, 2013.

MINISTÉRIO DA EDUCAÇÃO. Diretoria da Educação Básica Presencial. Coordenação de Aperfeiçoamento de Pessoal de Nível Superior. Relatório de Gestão 2009-2011: Pibid, 2012. Disponível

em:

<http://www.capes.gov.br/images/stories/download/bolsas/DEB_Pibid_Relatorio2009_2011.pdf>. Acesso em: 25 mar. 2013.

SANTANA, D. F.; CÔCO, D. Estágio Supervisionado e constituição da identidade docente. In: Jornada de Iniciação Científica, Desenvolvimento Tecnológico e Inovação do Ifes, VIII, 2013, Ifes Campus Serra. Anais. Serra - ES, 2013.

SEVERINO, A. J. A pesquisa em educação: abordagem crítico-dialética e suas implicações na formação do educador. In: CONTRAPONTO / Universidade do Vale do Itajaí, ano 1, n. 1, p. 11-22, Itajaí: Univali, jan./jun. 2001.

SHULMAN, Lee S. Conocimiento y enseñanza: fundamentos de La nueva reforma. Revista de currículum y formacíon del professorado, 2005, v. 9, n. 2. 